\title{
Resistance Training and Neuromuscular Performance in Seniors
}

\author{
Authors \\ Affliations
}

U. Granacher ${ }^{1}$, M. Gruber ${ }^{2}$, A. Gollhofer

Institute of Exercise and Health sciences, University of Basel, Basel, Switzerland

${ }^{2}$ Department of Training and Movement Science, University of Potsdam, Potsdam; Germany

${ }^{3}$ Institute of Sport and Sport Science, University of Freiburg, Freiburg, Cermany

Key words
aging
strength training
resistance training
maximal and explosive force
production
balance performance
postural control

Abstract

r

Age-related processes in the neuromuscular and the somatosensory system are responsible for decreases in maximal and explosive force production capacity and deficits in postural control. Thus, the objectives of this study were to investigate the effects of resistance training on strength performance and on postural control in seniors. Forty healthy seniors ( $67 \pm 1 \mathrm{yrs}$ ) participated in this study. Subjects were randomly assigned to a resistance training $(n=20)$ and a control group $(n=20)$. Resistance training for the lower extremities lasted for 13 weeks at $80 \%$ of the one repetition maximum. Pre and post tests included the measurement of maximal isometric leg extension force with special emphasis on the

\section{Introduction}

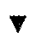

There have been substantial increases in the percentage of people aged 65 and older in societies of western industrial countries. This trend necessitates intense research attention into the effects of aging on neuromuscular performance and its functional consequences. Twenty-eight to thirtyfive per cent of individuals over the age of 65 years sustain at least one fall over a one-year period [2] and the occurrence increases to 32$42 \%$ in adults over the age of 75 years [33]. Numerous epidemiological studies have identified a multitude of risk factors for falling, like impaired depth perception, slow reaction time, and increased body sway [19]. In particular, deficits in postural control as well as decreases in strength and power of the lower extremities are important risk factors for falls in old age $[13,29]$. Era et al. [5] assessed static postural control on a force platform in a randomly selected sample of subjects aged 30 years and over. Differences in balance performance were already apparent
Correspondence

Dr. U. Granacher

Institute of Exercise and Health

University of Base

Birsstraße $320 \mathrm{~B}$

4052 Basel

Switzerland

Fax: $+41 / 61 / 3778731$

urs.granacher@unibas.ch
Tel.: $+41 / 61 / 3778735$ early part of the force-time-curve and the assessment of static (functional reach test) and dynamic (tandem walk test, platform perturbation) postural control. Resistance training resulted in an enhanced strength performance with increases in explosive force exceeding those in maximal strength. Improved performances in the functional reach and in the tandem walk test were observed. Resistance training did not have an effect on the compensation of platform perturbations. Increases in strength performance can primarily be explained by an improved neural drive of the agonist muscles. The inconsistent effect of resistance training on postural control may be explained by heterogeneity of testing methodology or by the incapability of isolated resistance training to improve postural control. among young ( 30 -39-year olds) and middle-aged adults (40-49-year olds) and became even more pronounced after the age of 60 years. In addition, Fernie et al. [7] investigated subjects aged over 63 years and observed that postural sway was significantly greater for those who fell one or more times in a year than for those who did not fall. The impact of neuromuscular aging is not only restricted to deficits in postural control, it also has an effect on maximal and explosive force production capacity. The average reported decline in maximal strength ranges from 20 to $40 \%$ between the ages of 30 to 80 years [21]. Recent data indicates that age-related impairments in explosive force production capacity exceed those in maximal strength with the most severe losses occurring between the seventh and ninth decade of life [20]. Interestingly, it has been shown that reduced leg power is an early indicator of balance deficits [26]. Furthermore, pijnappels et al. [29] observed an association between lower limb leg strength and the ability to prevent fall after a gait perturbation. Given the associa- 
tion between muscle weakness and deficits in postural control, it can be hypothesized that resistance training could attenuate or even reverse age-related impairments in both, strength performance and postural control. However, a recently published review on the efficacy of resistance training on balance performance in older adults provided limited support for the impact of resistance training in isolation on balance performance [28]. With the goal of further investigating this issue, the specific objectives of this study were to investigate the effects of heavy resistance strength training (HRT) on ( $a$ ) maximal and explosive force production capacity with special emphasis on the early part of the force-time-curve and $(b)$ on static and dynamic postural control in elderly men.

\section{Materials and Methods}

$\checkmark$

\section{Subjects}

Forty males between the ages of 60 and 80 years (mean age $67 \pm 1 \mathrm{yrs}$; body-mass-index $25.2 \pm 0.4 \mathrm{~kg} / \mathrm{m}^{2}$ ) provided written informed consent to participate in the study after experimental procedures were explained. Subjects were healthy with no history of serious muscular, neurological, cardiovascular, metabolic and inflammatory diseases. The participants can be classified as physically active with $10.3 \mathrm{~h}$ per week of daily and sports activities [9]. None of the subjects had previously participated in systematic strength training. Local ethical permission was given and all experiments were conducted according to the declaration of Helsinki.

\section{Training program}

The 40 subjects were randomly assigned to a heavy-resistance strength training group (HRT-group) and a control-group (CONgroup). Subjects of the HRT-group participated in a 13 week training program with three training sessions a week according to the ACSM position stand on resistance training for the elderly [6]. The first week was designed as a pre training period for subjects to become acquainted with the weight training machines and training intensity. Training was performed on alternate days so as to provide a sufficient resting period between sessions. Each session lasted for one hour and started with a $10 \mathrm{~min}$ warm up program on a bicycle ergometer at $80 \mathrm{~W}$. The HRT-group was provided a lower limb HRT regime at $80 \%$ of their one repetition maximum ( $1 \mathrm{RM}$ ) on the leg press, the leg-extension, the calfraise, and a cable column for exercising foot dorsiflexors. Subjects performed three sets of ten repetitions for each exercise. Subjects rested for two minutes between sets. Training intensity ( $80 \%$ of the $1 \mathrm{RM}$ ) was examined for each subject on a weekly basis and the training load was adjusted according to the $1 \mathrm{RM}$ test. All training sessions ended with a ten minute cool down period which consisted of riding on a bicycle ergometer at $80 \mathrm{~W}$. All sessions were documented and supervised by the authors of the study. The CON-group did not receive any intervention.

\footnotetext{
Pesting protocol and apparatus

Pre-and post measurements were conducted in our biomechanic laboratory. Test circumstances (e.g., room illumination, temperture, noise) were in accordance with recommendations for posturographic testing [16]. The testing protocol included $(a)$ clinical (function the assessment of static and dynamic postural control applicanal reach test (FRT), tandem walk test (TWT)), (b) the
}

ing platform, and $(c)$ the assessment of maximal isometric leg extension force (MIF) on a leg press. This testing sequence was applied in order to keep the effects of neuromuscular fatigue minimal.

\section{Clinical tests}

Static postural control was assessed by means of the functional reach test [4]. For this purpose, we constructed a moveable sliding apparatus which allowed the determination of the maximal distance one can reach forward beyond arm's length while maintaining a fixed base of support in the standing position. The first two trials were performed to familiarize subjects with the FRT. Trials three and four were averaged and taken for further analysis. Reach forward distances between 15.4 and $25.4 \mathrm{~cm}$ indicate a moderate risk of falling [4]. Dynamic postural control was assessed by means of the TWT [24]. Subjects were asked to walk ten steps (heel to toe) at a self selected speed on a straight $2 \mathrm{~cm}$ wide line which was attached on the floor. Hands rested on the hips and subjects had to look straight forward to a cross attached to the wall. The number of successful steps on the line were calculated in forward and backward direction and taken for further analysis. Three trials were performed in forward and backward direction and averaged for each direction.

\section{Medio-lateral perturbation impulse}

This test involved a one-legged postural stabilization task on a two-dimensional platform (Posturomed, Haider, Bioswing, Pullenreuth, Germany). The platform is mounted to four springs and is only free to move in the transversal, medio-lateral, and anterior-posterior directions. The maximal natural frequency of the Posturomed is below $3 \mathrm{~Hz}$. The mechanical constraints and the reliability of the system were described earlier [23]. If the platform is in neutral position, the maximum range of motion in the anterior-posterior (ap) and medio-lateral ( $\mathrm{ml}$ ) directions amounts to $70 \mathrm{~mm}$ respectively. Medio-lateral perturbation impulses were applied in order to investigate quasi dynamic postural control of the subjects. Therefore, the platform was moved $2.5 \mathrm{~cm}$ from the neutral position in the medio-lateral direction, where it was magnetically fixed. For experimental testing, subjects were asked to stand on one leg on the fixed platform with their supported leg in $30^{\circ}$ flexion, hands placed on hips and gaze fixated on a cross on the wall. Several trials helped participants to get accustomed to the measuring device. After investigators visually controlled the position of the subjects, the medio-lateral perturbation impulse was unexpectedly applied by detaching the magnet. The platform suddenly accelerated in the medial direction. The subjects' task was to damp the oscillating platform by balancing unilaterally on the Posturomed. Summed oscillations of the platform in $\mathrm{ml}$ and ap were assessed by means of a joystick like 2D potentiometer (Megatron) which was connected to the platform. The potentiometer measured the position of the platform in degrees $\left[^{\circ}\right]$. The signal was differentiated, rectified and integrated over the 10 s test interval. Three trials were performed. The best trial (least oscillations in $\mathrm{ml}$ direction) was used for further analysis (0 Fig. 2).

\section{Leg-press}

MIF was measured on a leg-press, with each foot resting on a one-dimensional force platform (Kistler). Subjects were horizontally positioned on the sledge of the leg-press with hip and knee angle adjusted at $90^{\circ}$. The waist was fixed and subjects were allowed to stabilize their upper body by holding on to han- 
dles attached to the leg-press. Subjects were instructed to avoid forced respiration during maximal efforts. Before the testing started, subjects became accustomed to the testing procedure by doing a warm-up consisting of three to five submaximal isometric actions. Thereafter, each subject performed three to four leg-press exercises with maximal voluntary effort. For each trial, subjects were thoroughly instructed to act as forcefully and as fast as possible. The force signal perpendicular to the force plate was sampled at $500 \mathrm{~Hz}$. The raw force signals were analogue-todigital converted and stored on a PC. During later offline analysis, the trial with MIF was selected and the force signal was filtered by a digital fourth order recursive Butterworth low-pass filter, using a cutoff frequency of $50 \mathrm{~Hz}$. Onset of force was determined at $2 \%$ of each individual's MIF. MIF and RFD were calculated from the individual maximal isometric force development record. MIF was defined as the maximal voluntary force value of the force-time curve, determined under isometric condition. $\mathrm{RFD}_{\max }$ was defined as the maximal slope at deflection of the

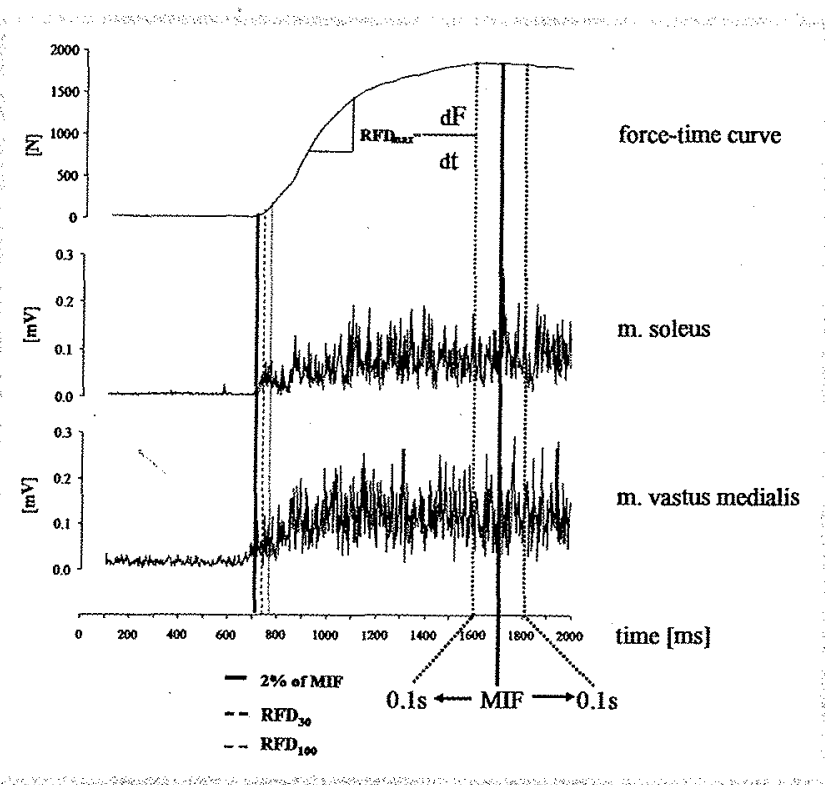

Fig. 1 Force and rectified electromyographic signals of $m$. soleus and $\mathrm{m}$. vastus medialis of one subject recorded during a trial of maximal isometric leg extensor action in the leg-press. force-time curve ( $\Delta$ force/ $\Delta$ time). In addition, $R F D_{30}$ and $R F D_{100}$ were calculated as the mean slope of the force-time curve over the time interval $0-30 \mathrm{~ms}$ and $0-100 \mathrm{~ms}$ ( 0 Fig. 1 ).

\section{Electromyography (EMG)}

Circular bipolar surface electrodes (Hellige ${ }^{\circledR}$, type 44008347 $\mathrm{Ag} / \mathrm{AgCl}$ ) (diameter $10 \mathrm{~mm}$, center to center distance $25 \mathrm{~mm}$ ) were placed over $m$. tibialis anterior (TA), $m$. soleus $(\mathrm{SO}), \mathrm{m}$. peronaeus (PE), and $\mathrm{m}$. vastus medialis (VM) of the right leg. The longitudinal axes of the electrodes were in line with the direction of the underlying muscle fibers. The reference electrode was attached to the patella. All electrode positions were carefully determined and marked with a waterproof felt tip pen on the skin to enable precise electrode application in the post tests. If necessary, markers were retraced during the training sessions. In a previous study [12], the applied EMG parameters proved to be reliable under similar test conditions. Interelectrode resistance was kept below $5 \mathrm{k} \Omega$ by shaving, slightly roughening, degreasing and disinfecting the skin. EMG signals were sampled at $500 \mathrm{~Hz}$, amplified and bandpass filtered $(10-1000 \mathrm{~Hz})$ and were carefully monitored for artifacts, noise and cross-talk. EMG data were quantified by integrating and time normalizing the full-wave rectified, as well as averaged EMG-signals (mean amplitude voltage (MAV)). In terms of the medio-lateral perturbation impulse, MAV of TA and PE were analyzed in the time interval of $10 \mathrm{~s}$ following the release of the magnet ( $\mathrm{Fig}$. 2). With respect to MIF, MAV of SO and VM were analyzed in the time intervals $0-30 \mathrm{~ms}, 0-100 \mathrm{~ms}$, and $100 \mathrm{~ms}$ pre and post MIF (० Fig. 1).

\section{Statistical analysis}

Data are presented as group mean values \pm SE. Due to the design of our study, data were analysed in a 2 group (HRT, CON) $\times 2$ testing session (Pre--, Post-Test) analysis of variance with repeated measures on testing session after normal distribution was examined (Kolmogorov-Smirnov-test). In addition, pre training differences between the two experimental groups were calculated in all analysed parameters by means of the multivariate general linear model. The classification of effect sizes was determined by calculating partial $\eta_{p}^{2}$. The significance level was set at $p<0.05$. All analyses were performed using Statistical Package for Social Sciences (SPSS) version 16.0 .

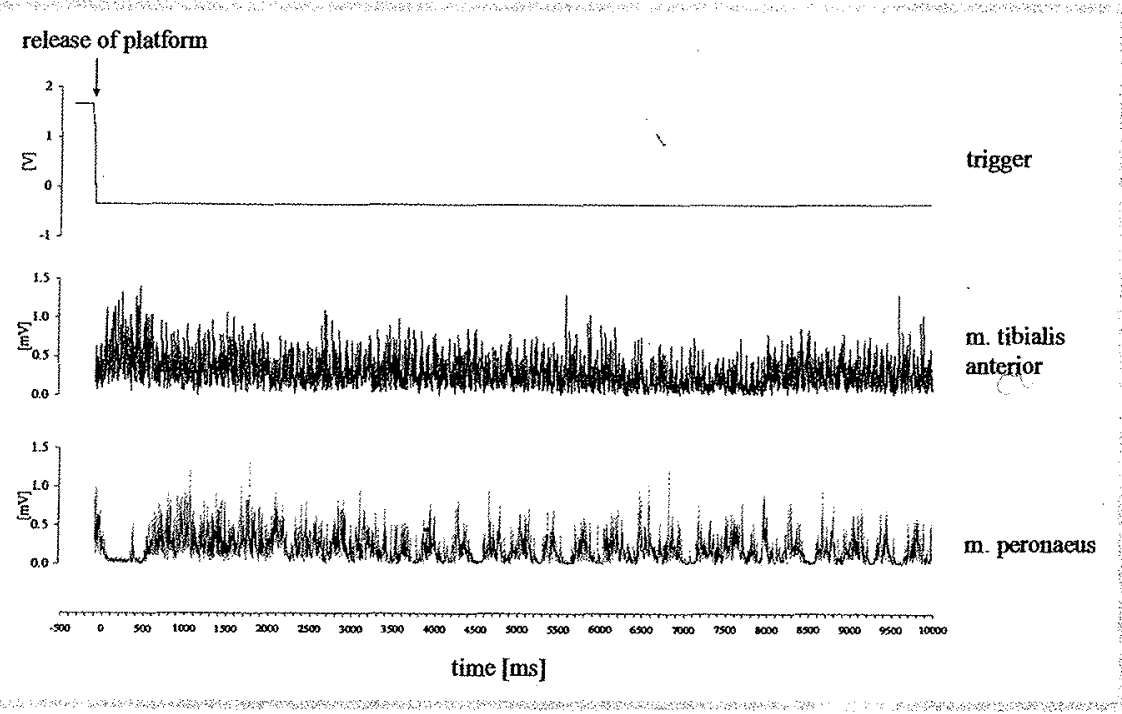

Fig. 2 Rectiffed electromyographic signals of $\mathrm{m}$. tibialis anterionand m peronaeus of one subject during the compensation of the medio-lateral perturbation impulse on the Posturomed. 


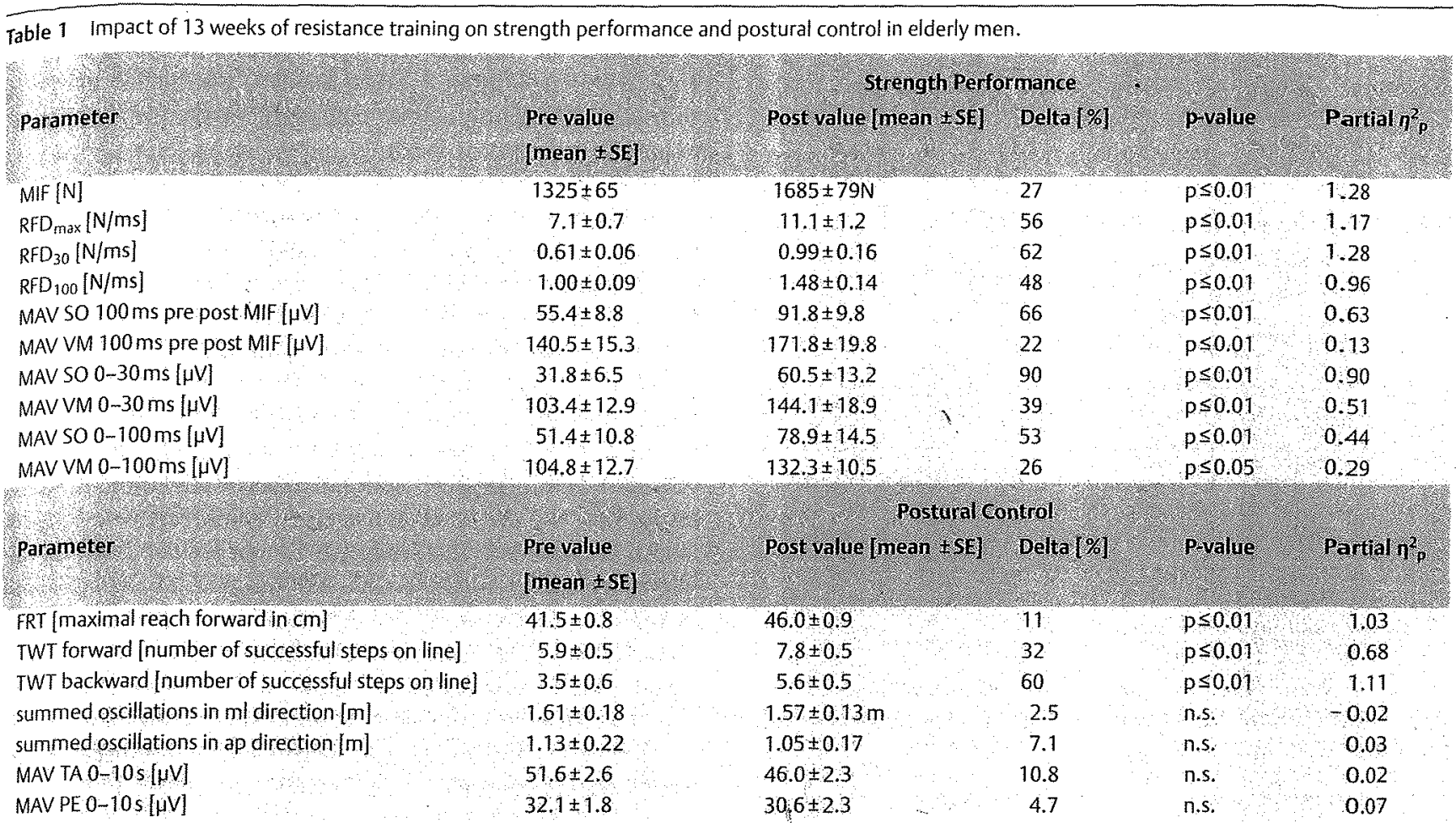

$\mathrm{MF}=$ maximal isometric leg extension force, $\mathrm{RFD}_{\max }=$ maximal rate of force development; $\mathrm{RFD}_{30}$ = mean slope of the force time curve over the time interval $0-30$ ms; $\mathrm{RFD}_{100}=$ mean slope of the force time curve over the time interval 0-100 ms; MAV $50100 \mathrm{~ms}$ pre post MIF=mean amplitude voltage of m. soleus in the time interval $100 \mathrm{~ms}$ pre and post MIF, MAV VM $100 \mathrm{~ms}$ pre post MIF = mean amplitude voltage of $\mathrm{m}$. vastus medialis in the time interval $100 \mathrm{~ms}$ pre and post MIF, MAV SO $0-30 \mathrm{~ms} \approx \mathrm{mean}$ amplitude voltage of $\mathrm{m}$. soleus during maximal isometric leg extension in the time interval $0-30 \mathrm{~ms}$; MAV VM 0-30 ms $=$ mean amplitude voltage of $\mathrm{m}$. vastus medialis during maximal isometric leg extension in the time interval $0-30 \mathrm{~ms}$; MAV SO 0-100 ms $=$ mean amplitude voltage of $\mathrm{m}$. soleus during maximal isometric leg extension in the time interval $0-100 \mathrm{~ms}$ : MAV VM 0-100 ms = mean amplitude voltage of $\mathrm{m}$. vastus medialis during maximal isometric leg extension in the time interval $0-100 \mathrm{~ms}$, FRT $=$ functional reach test, TWT=tandem walk test, MAV TA 0-10s = mean amplitude voltage of $m$. tibialis anterior during the medio-lateral perturbation impulse in the time interval $0-10$ s, . MAV PE $0-10 \mathrm{~s}=$ mean amplitude voltage of $\mathrm{m}$. peronaeus during the medio-lateral perturbation impulse in the time interval $0-10 \mathrm{~s}, \mathrm{n} . \mathrm{s} .=$ non significant

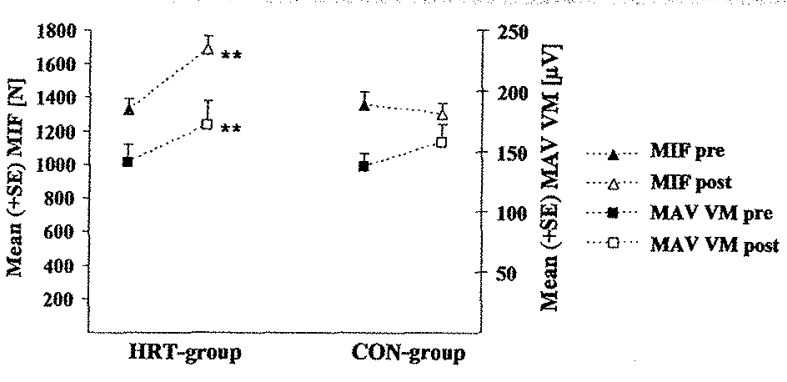

Fig. 3 Maximal isometric leg extension force (MiF) expressed in $\mathrm{N}$ (mean + SE) before (dark triangle) and after (light triangle) the training period and mean amplitude voltage (MAV) of $m$. vastus medialis (VM) expressed in $\mu \vee$ (mean $+S E$ ) in the time interval $100 \mathrm{~ms}$ pre and post MIF before (dark square) and after (light square) the training period, The dashed lines indicate that pre to post changes are not necessarily linear. HRT-group stands for the heavy resistance strength training group; CONgroup for the control-group. Pre- to post training differences: ${ }^{*} p<0.01$.

\section{Resulfs}

Following 13 weeks of training, maximal and explosive force production capacity were significantly enhanced in the HRTgroup with increases in $R F D_{\max }, R \mathrm{DD}_{30}$, and $R F D_{100}$ exceeding those in MIF ( Table 1, 0 Figs. 3,4 ). In addition, neural activation of SO and VM were significantly enhanced in the time intervals $100 \mathrm{~ms}$ pre and post MIF, onset of force to $30 \mathrm{~ms}(0-30 \mathrm{~ms})$, and onset of force to $100 \mathrm{~ms}(0-100 \mathrm{~ms})$ (० Table 1 , 0 Figs. 3,4$)$. Furthermore, static and dynamic postural control, assessed by

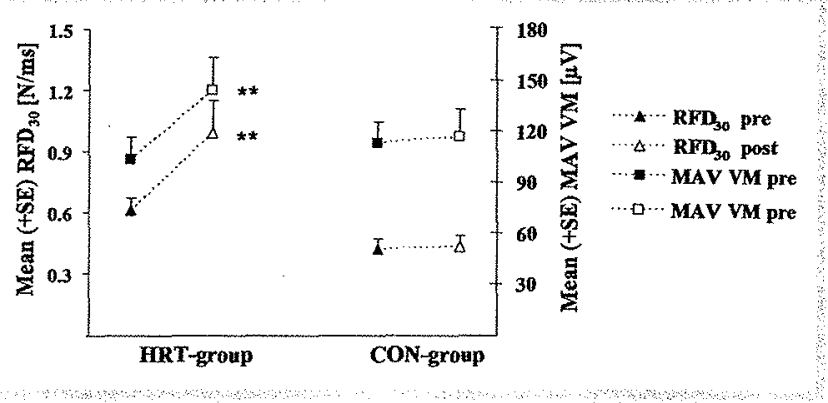

Fig. 4 Mean slope of the force time curve in the time interval from onset of force to $30 \mathrm{~ms}\left(\mathrm{RFD}_{30}\right)$ expressed in $\mathrm{N} / \mathrm{ms}$ (mean $+\mathrm{SE}$ ) before (dark trangle) and after (light triangle) the training period and mean amplitude voltage (MAV) of $m$. vastus medialis (VM) expressed in $\mu \mathrm{V}$ $($ mean $+\mathrm{SE})$ in the time interval from onset of force to $30 \mathrm{~ms}$ before (dark square) and after (light square) the training period. The dastied lines indicate that pre to post changes are not necessarily linear. HRT group stands for the heavy resistance strength training group; CON-group for the control-group. Pre-to post training differences: ${ }^{* *} p<0.01$.

means of the FRT and TWT, were significantly improved in the HRT-group after training ( $\bullet$ Table 1, $\bullet$ Fig. 5). However, HRT did not have an impact on quasi-dynamic postural control in terms of the compensation of the medio-lateral perturbation impulse on the Posturomed. Thus, summed oscillations of the platform in $\mathrm{ml}$ and ap directions and neural activation of the TA and PE were not significantly changed after training ( $O$ Table 1 , - Fig. 5). No significant differences in pre values of the analysed parameters were observed between the experimental groups. 


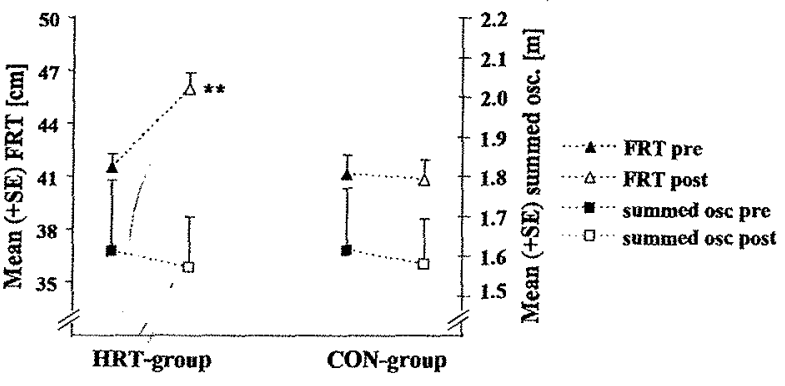

Fig. 5. Performance in the functional reach test (FRT) expressed in $\mathrm{cm}$ (mean + SE) before (dark triangle) and after (light triangle) the training period and summed oscillations of the Posturomed platform in mediofateral direction expressed in $m(m e a n+S E)$ in the time interval from the release of the platform to $10 \mathrm{~s}$ before (dark square) and after (light square) the training period. The dashed lines indicate that pre to post changes are not necessarly linear. HRT-group stands for the heavy resistance strength training group, $\mathrm{CON}$ group for the control-group. Preto post training differences: ${ }^{*} \mathrm{p}<0,01$.

With respect to the CON-group, no significant changes could be detected in the analysed parameters.

\section{Discussion}

In this study, HRT resulted in a significantly improved maximal and explosive force production capacity with increases in explosive force exceeding those in maximal strength. In addition, an improved static and dynamic postural control was observed in clinical (FRT, TWT) but not in biomechanical (medio-lateral perturbation impulse) tests. The observed results concerning the impact of HRT in old age on strength performance are in accordance with literature. It has frequently been observed, that even in this age group, strength training results in an increase in maximal as well as explosive force production capacity [25]. In addition, a meta-analysis on the impact of progressive resistance training in older adults on strength performance of the leg extensors revealed an effect size of 0.68 [18]. Given that the ability to generate force rapidly is, from a fall preventive point of view, more relevant than the capacity to produce maximal strength [32], it is of paramount importance to apply strength training programs which have the potential to enhance explosive force production capacity. Recently, it has been suggested that high-speed power training has a greater impact on explosive force production capacity in the elderly than HRT [22]. Miszko et al. [22] compared power training to strength training in older community-dwelling adults. They observed that adaptive processes were specific to the type of training, i.e., power trainers increased power, and strength trainers increased strength to a greater extent. However, in another study, it has been reported that muscle power and muscle strength improved similarly following 24 weeks of high-speed power training or HRT [14]. In addition, the outcomes of the present study do not support the results of Miszko et al. [22], because HRT had a greater impact on explosive force than on maximal strength ( 0 Table 1). A reason for this might be that individuals with initial low strength levels may see improvements throughout the force velocity spectrum even though HRT and not power training was applied [17]. Furthermore, since age-related decreases in explosive force exceed those in maximal strength [20], levels of explosive force are particularly low in seniors. This low base level could be responsible for the observed high increases in explosive force Thus, it seems plausible to argue that HRT is a feasible, effective, and safe training program for older adults if the primary goal is to induce increases in maximal and explosive force production capacity.

The question of underlying neuromuscular mechanisms responsible for the observed gains in maximal and explosive force production capacity following HRT, also warrants attention. Based on the results of this study and with reference to literature [30], it can be hypothesized that strength gains can be attributed primarily to increased agonist neural drive. EMG measurements taken from the VM during maximal isometric leg extension action showed increases from 22-39\% compared to pre training values. Training induced muscle hypertrophy could also be responsible for the observed strength gains. Due to methodological limitations of this study, we can not predict the influence of an increase in muscle cross-sectional area on the improved strength performance. Other investigators used imaging techniques (MRI- and CT-scan) and found enlargements of cross-sectional area in muscles of the upper and lower extremities of $5-17 \%$ in the elderly after resistance training lasting $\sim 3$ months $[3,8]$. Thus, predominately neural factors but also muscle hypertrophy could account for the observed strength gains.

The results of the present study concerning the effects of HRT in seniors on postural control are heterogeneous and thus in accordance with literature. In a recent systematic review on the efficacy of progressive resistance training on balance performance in older adults [28], only 14 studies of the 29 studies reviewed reported that the resistance training group performed from $2-98 \%$ better than the con-group in a balance outcome. Interestingly, studies that included multiple balance tests have shown significant improvements in one or some, but not every, balance test [28]. Thus, heterogeneity in balance testing methodology could be one reason for the observed discrepancies in the literature. Future studies should therefore provide comparable data by applying similar balance tests.

The inconsistency in literature is illustrated in the present study in an enhanced performance in the FRT and the TWT and no significant changes in the ability to compensate for a medio-lateral perturbation impulse following HRT. This is reinforced by a meta-analysis on the impact of resistance training in old age on postural control [18]. Latham et al. [18] could not find a clear effect of resistance training on various measures of standing balance among 789 participants (effect size $=0.11$ ).

The investigated improvements in the FRT and the TWT are in accordance with two other studies $[31,15]$. Sousa and Sampaio [31] found a $13 \%$ increase in performance of the FRT, jette et al. [15] investigated a $20 \%$ increase in performance of the TWT following resistance training. The absence of a training-induced effect of HRT on the ability to compensate for a medio-lateral perturbation impulse is in accordance with a study conducted by Bellew et al. [1]. These authors investigated the impact of resistance training in seniors on quasi dynamic postural control by means of applying an upward directed perturbation impulse (dorsiflexion of foot) while subjects were standing on a platform. Twelve weeks of resistance training did not have a positive effect on balance performance. Furthermore, Granacher et al. [10] could not find an impact of HRT in elderly men on the ability to compensate for perturbation impulses while walking on a treadmill. The observed discrepancy in this study and in literature concerning the effects of resistance training on postural control 
may be explained by heterogeneity of cohort and balance tests, variability in methodology of the applied balance tests and sample size, inadequate training methods and/or compliance to training, or lack of statistical power [28]. In addition, Orr et al. 28] point out that resistance training alone could not have the potential to induce improvements in balance control. Thus, resistance with different training loads and/or contraction velocities as well as other training regimes (i.e., balance training) should be considered which might be more efficient in terms of their impact on postural control in old age. In fact, recent studies indicate that strength training combined with modified power type of exercises or even high speed power training seem to have a greater impact on balance performance and ADL in old age than traditional heavy resistance strength training $[22,27]$. In addition, exercise programs that include balance training components have tended to be most effective in their impact on strength performance and postural control. Preliminary results indicate that balance training has an effect on maximal and explosive force production capacity of the lower extremities and functional reflex activity during gait perturbations in seniors $[10,11]$.

In conclusion, HRT is a feasible, effective, and safe training program to induce gains in maximal and explosive force production capacity. However, the application of HRT in old age might not be appropriate if the primary goal is to induce improvements in postural control. Thus, alternative and more efficient training regimes should be administered. There is evidence that high speed power training and balance training have the capacity to improve strength performance and postural control in old age and thereby prevent elderly people from falling.

\section{References}

1 Bellew $J W$, Yates $J W$, Gater $D R$. The initial effects of low-volume strength training on balance in untrained older men and women. J Strength Cond Res 2003; 17: 121-128

2 Blake AJ, Morgan K, Bendall MJ, Dallosso H, Ebrahim SB, Arie TH, Fentem PH, Bassey EJ. Falls by elderly people at home: prevalence and associated factors. Age Ageing 1988; 17: 365-372

3 Brown AB, McCartney N, Sale $D G$. Positive adaptations to weight-lifting training in the elderly. J Appl Physiol 1990; 69: 1725-1733

4 Duncan PW, Studenski S, Chandler J, Prescott B. Functional reach: predictive validity in a sample of elderly male veterans. J Gerontol 1992; 47: M93-M98

5 Era $P$, Sainio $P$, Koskinen $S$, Haavisto P, Vaara M, Aromaa A. Postural balance in a random sample of 7979 subjects aged 30 years and over. Gerontology 2006; 52: 204-213

6 Evans WJ. Exercise training guidelines for the elderly. Med Sci Sports Exerc 1999; $31: 12-17$

7 Fernie GR, Gryfe CI, Holliday PJ, Llewellyn A. The relationship of postural sway in standing to the incidence of falls in geriatric subjects. Age Ageing 1982; 11: 11-16

8 Ferri A, Scaglioni G, Pousson M, Capodaglio P, Van Hoecke J, Narici MV. Strength and power changes of the human plantar flexors and knee extensors in response to resistance training in old age. Acta Physiol Scand 2003; 177: 69-78

9 Frey I, Berg A, Grathwohl D, Keul J. Freiburg Questionnaire of physical activity-development, evaluation and application. Soz Praventivmed 1999; 44: 55-64

10 Granacher $U$, Gollhofer $A$, Strass $D$. Training induced adaptations in characteristics of postural reflexes in elderly men. Gait Posture 2006; 24: 459-466

11 Granacher U, Gruber M, Strass D, Gollhofer A. Die Auswirkungen von sensomotorischem Training im Alter auf die Maximal- und Explosivkraft. Deut Z Sportmed 2007; 12: 446-451
12 Gruber $M$, Gollhofer A. Impact of sensorimotor training on the rate of force development and neural activation. Eur J Appl Physiol 2004; 92: $98-105$

13 HausdorfJJM, Nelson ME, Kaliton D, Layne JE, Bernstein MJ, Nuernberger A, Singh MA. Etiology and modification of gait instability in older adults: a randomized controlled trial of exercise. J Appl Physiol 2001; 90: $2117-2129$

14 Henwood $T R$, Riek $S$, Taaffe $D R$. Strength versus muscle power-specific resistance training in community-dwelling older adults. J Gerontol A Biol Sci Med Sci 2008; 63: 83-91

15 Jette AM, Lachman M, Giorgetti MM, Assmann SF, Harris BA, Levenson $C$, Wernick $M$, Krebs $D$. Exercise - it's never too late: the strong-for-life program. Am J Public Health 1999; 89: 66-72

16 Kapteyn TS, Bles W, Njiokiktjien CJ, Kodde L, Massen CH, Mol JM. Standardization in platform stabilometry being a part of posturography. Agressologie 1983; 24: 321-326

17 Komi PV, Häkkinen K. Strength and power, In: Dirix A, Knuttgen HG, Tittel K, eds. The Olympic Book of Sports Medicine. Boston: Blackwell Scientific; 1988; 181-193

18 Latham NK, Bennett DA, Stretton CM, Anderson CS. Systematic review of progressive resistance strength training in older adults. J Gerontol A Biol Sci Med Sci 2004; 59: 48-61

19 Lord SR, Dayhew J. Visual risk factors for falls in older people. J Am Geriatr Soc 2001; 49: 508-515

20 McNeil CJ, Vandervoort AA, Rice CL. Peripheral impairments cause a progressive age-related loss of strength and velocity-dependent power in the dorsiflexors. J Appl Physiol 2007; 102: 1962-1968

21 Merletti R, Farina D, Gazzoni M, Schieroni MP. Effect of age on muscle functions investigated with surface electromyography. Muscle Nerve 2002; 25: 65-76

22 Miszko TA, Cress ME, Slade JM, Covey CI, Agrawal SK, Doerr CE. Effect of strength and power training on physical function in communitydwelling older adults. J Gerontol A Biol Sci Med Sci 2003; 58: 171175

23 Mueller O, Guenther M, Krauss I, Horstmann T. Physical characterization of the Posturomed as a measuring device-Presentation of a procedure to characterize balance capabilities. Biomed Tech 2004; 49: 56-60

24 Nelson ME, Fiatarone MA, Morganti CM, Trice I, Greenberg RA, Evans $W J$. Effects of high-intensity strength training on multiple risk factors for osteoporotic fractures. A randomized controlled trial. JAMA 1994; 272: $1909-1914$

25 Newton RU, Häkkinen $K$, Häkkinen A, McCormick M, Volek J, Kraemer WJ. Mixed-methods resistance training increases power and strength of young and older men. Med Sci Sports Exerc 2002; 34: 1367-1375

26 Orr $R$, de Vos $N$, Singh $N$, Ross $D$, Stavrinos $T$, Fiatarone-Singh $M$. Novel relationships of balance to muscle power and mental health in healthy older adults. J Am Geriatr Soc 2004; 52 (Suppl.): 17

27 Orr R, de Vos NJ, Singh NA, Ross DA, Stavrinos TM, Fiatarone-Singh MA. Power training improves balance in healthy older adults. J Gerontol $A$ Biol Sci Med Sci 2006; 61: 78-85

28 Orr $R$, Raymond J, Fiatarone SM. Efficacy of progressive resistance training on balance performance in older adults : a systematic review of randomized controlled trials. Sports Med 2008; 38: 317-343

29 Pijnappels $M$, van der Burg PJ, Reeves $N D$, van Dieen $J H$. Identification of elderly fallers by muscle strength measures. Eur J Appl Physiol 2008; 102: 585-592

30 Reeves ND, Maganaris $C N$, Narici MV. Plasticity of dynamic muscle performance with strength training in elderly humans. Muscle Nerve 2005; $31: 355-364$

31 Sousa $\mathrm{N}$, Sampaio J. Effects of progressive strength training on the performance of the Functional Reach Test and the Timed Get-Up-andGo Test in an elderly population from the rural north of Portugal. Am J Hum Biol 2005; 17: 746-751

32 Suetta C, Magnusson SP, Beyer N, Kjaer M. Effect of strength training on muscle function in elderly hospitalized patients. Scand J Med Sci Sports 2007; 17: 464-472

33 Tinetti ME, Speechley $M$, Ginter SF. Risk factors for falls among elderly persons living in the community. N Engl J Med 1988; 3̦19: 1701-1707 